\title{
Composição Químico-Bromatológica de Variedades de Cana-de-Açúcar (Saccharum spp L.) com Diferentes Ciclos de Produção (Precoce e Intermediário) em Três Idades de Corte
}

\section{Alberto Magno Fernandes ${ }^{1}$, Augusto César de Queiroz ${ }^{2}$, José Carlos Pereira ${ }^{2}$, Rogério de Paula Lana ${ }^{3}$, Marcio Henrique Pereira Barbosa ${ }^{4}$, Dilermando Miranda da Fonseca ${ }^{3}$, Edenio Detmann $^{6}$, Luciano da Silva Cabral ${ }^{6}$, Elzânia Sales Pereira ${ }^{5}$, Andréa Vittori ${ }^{6}$}

RESUMO - Foram objetivos deste trabalho determinar a composição químico- bromatológica, as frações potencialmente degradável $\left(\mathrm{B}_{2}\right)$ e indegradável $(\mathrm{C})$ da FDN dos carboidratos totais e estimar a repleção ruminal da cana-de-açúcar com diferentes ciclos de produção (precoce e intermediário), em três idades de corte (426, 487 e 549 dias). As análises laboratoriais consistiram na determinação da matéria seca (MS), matéria orgânica, matéria mineral, proteína bruta (PB), extrato etéreo, lignina, fibra em detergente neutro (FDN), FDN corrigida para cinzas e proteína, fibra em detergente ácido (FDA), proteína insolúvel em detergente neutro, proteína insolúvel em detergente ácido e proteína solúvel em detergente neutro. Os nutrientes digestíveis totais (NDT) foram calculados por intermédio da composição química. As frações $\mathrm{B}_{2}$, $\mathrm{C}$ e a taxa de digestão da fibra, bem como a repleção ruminal, foram estimadas através de parâmetros cinéticos obtidos a partir da incubação in situ. O avanço da idade de corte propiciou aumento nos teores de MS em 9,5\%. As variedades intermediárias apresentaram NDT superiores às precoces, as quais destacaram-se pelos mais elevados teores de FDN e FDA, cujos respectivos valores foram 487,56 e 471,03, e 287,87 e 247,54 g/kg MS para as variedades precoces e intermediárias, respectivamente. O NDT aumentou linearmente com a idade de corte, variando de 62,45 a 63,50\%; contudo, os teores de FDN e FDA apresentaram comportamento quadrático. As variedades precoces apresentaram maior teor de PB que as intermediárias somente na idade ao corte de 549 dias, contrariamente, o teor de brix foi superior para as variedades intermediárias no último corte. As variedades precoces apresentaram maior repleção ruminal total e menor taxa de digestão da fibra. A fração $\mathrm{B}_{2}$ da fibra, foi reduzida e a $\mathrm{C}$ foi linearmente aumentada com a idade das plantas.

Palavras-chave:cana-de-açúcar, composição química, ciclos de produção, idades ao corte, parâmetros cinéticos

\section{Chemical Composition of Sugar Cane Varieties (Saccharum spp 1.) with Different Cycles of Production in Three Cut Time}

\begin{abstract}
The objectives of this work were to determine the chemical composition, the potentialy degradable fraction of NDF $\left(\mathrm{B}_{2}\right)$ and undegradable fraction $(\mathrm{C})$ and to estimate the ruminal fill of sugar cane with different cycles of production (early and intermediate), in three cut times (426, 487 and 549 days). The laboratorial analysis consisted in dry matter (DM), organic matter, ash, crude protein (CP), ether extract, lignin, neutral detergent fiber (NDF), neutral detergent fiber corrected for ash and protein, acid detergent fiber (ADF), neutral detergent insoluble protein, acid detergent insoluble protein and neutral detergent protein soluble. The TDN was calculated by chemical composition. The degradable and undegradable fractions, and fiber digestion rate, as well as the ruminal fill were estimated by kinetic parameters obtained throught in situ incubation. The advanced cut time increased the DM in 9.5\%. The intermediate varieties presented higher TDN than early varieties, which had the highest contents of NDF and ADF, whose respective values were 487.56 and 471.03 , and 287.87 and $247,54 \mathrm{~g} / \mathrm{kg}$ DM for the early and intermediate varieties, respectively. The TDN increased linearly with the cut time, varying from 62.45 to $63.50 \%$; however the NDF and ADF contents presented quadratic behavior. The early varieties presented higher content of CP than the intermediate only in the cut time of 549 days; contrarily, the brix of the sugar cane was superior to the intermediate varieties in the last cut. The early varieties presented larger total ruminal fill and lower fiber digestion rate. The degradable fraction of the fiber was reduced and the undegradable fraction was linearly increased with the age of the plants.
\end{abstract}

Key Words: chemical composition, cut time, kinetic parameters, cycles of production, sugar cane

\footnotetext{
1Zootecnista, DS. E.mail: alberto@uenf.br

2 Professor Titular, DZO-UFV E.mail: aqueiroz@mail.ufv.br

3 Professor Adjunto, DZO-UFV.

4 Professor Adjunto, DFT-UFV.

5 Professora UNEOESTE.

6 Estudante de Doutorado, DZO-UFV.
} 


\section{Introdução}

No Brasil, as pastagens constituem a maneira mais prática e econômica de fornecer alimentos aos bovinos. Porém, aproximadamente $80 \%$ da matéria seca das forragens produzidas nas pastagens, durante o ano, está disponível na estação quente e chuvosa, tornando-se a estação fria e seca um período crítico, no qual a produção de forragens é insuficiente, daí a necessidade de ser complementada com outras fontes de alimentos. Dessa forma, a produtividade animal, nos sistemas extensivos, varia de acordo com a oferta de pasto, permitindo ganhos razoáveis numa época e perda de peso em outra. No período seco, adicionalmente à redução na disponibilidade do pasto, ocorre redução na sua qualidade, sendo estes fatores os principais responsáveis pelos baixos índices zootécnicos observados nos rebanhos brasileiros.

A suplementação nutricional na época seca é uma alternativa para minimizar a perda de peso ou favorecer o ganho. Entretanto, a suplementação concentrada, além de aumentar o custo de produção, não consegue superar os efeitos negativos da baixa qualidade do pasto. Dessa forma, a cana-de-açúcar tem sido ferramenta importante na estação seca do ano, uma vez que se destaca pela elevada produção de matéria seca por hectare (Boin et al., 1987), é uma cultura relativamente fácil de se conduzir, tem boa aceitação pelos animais (Peixoto, 1964, citado por Carvalho, 1992) e elevado teor de carboidratos solúveis e, principalmente, pela sua disponibilidade no período seco, sem que haja queda no seu valor nutricional (Preston, 1986; Leng, 1988), justificando o fato de que, na maioria das propriedades rurais brasileiras, figura como uma das forrageiras mais exploradas, ainda que ocupando pequenas áreas (Carvalho, 1992).

A cana-de-açúcar apresenta características que limitam a sua utilização por animais de elevado potencial genético, dentre as quais destacam-se o baixo teor de proteína bruta (PB), fibra de lenta degradação ruminal e elevado teor de fibra não-degradável, o que limita a ingestão de alimentos (Pereira et al., 2001).

Embora o Brasil detenha a condição de maior produtor mundial (aproximadamente $24 \%$ do total) de cana-de-açúcar, em aproximadamente 4 milhões de hectares cultivados (Lima \& Mattos, 1993), e seja muito utilizada por pequenos e médios produtores na alimentação dos bovinos, não se encontra facilmente na literatura uma avaliação bromatológica relativa à variação no ciclo de produção e na idade de corte. Porém, ao adotarem critérios para indicar uma variedade de cana-de-açúcar como forrageira não foi levado em conta o valor nutritivo da variedade, mas, tão somente se baseavam em aspectos de produção (Peixoto, 1986). Entretanto, em estudos mais recentes (Aroeira, et al. 1993; Pereira et al., 1996; Miranda et al. 1999; Rodrigues et al. 1999; Pereira et al., 2001; Ludovico \& Mattos, 1997), diversas análises bromatológicas, bem como fracionamento e cinética de degradação dos carboidratos, foram realizadas para a avaliação nutricional da cana-de-açúcar. Apesar disso, outras avaliações, considerando-se o ciclo de produção e a idade de corte dessa forrageira, são importantes.

O uso da cana-de-açúcar como alimento para os animais, no período de escassez das pastagens, só não tem sido mais freqüente porque é pouco estudada para esta finalidade, principalmente quanto à definição de variedades com ciclos de produção diferentes, que sejam mais adequados à produção de forragem e ao seu manejo.

Objetivou-se, portanto, neste trabalho, determinar a composição químico-bromatológica, as frações potencialmente degradável $\left(\mathrm{B}_{2}\right)$ e indegradável $(\mathrm{C})$ da FDN dos carboidratos totais e estimar a repleção ruminal da cana-de-açúcar com diferentes ciclos de produção, em três idades de corte.

\section{Material e Métodos}

As variedades de cana-de-açúcar (Saccharum spp.) avaliadas neste estudo foram: RB765418, RB 855453, RB 855336, SP 80-1842 e SP 81-1763, RB 855113, RB 739359, RB 867515, SP 79-2233 e SP 79-1011; colhidas manualmente, de maneira aleatória, nas glebas do Campo Experimental de Oratórios, pertencente à Usina de Jatiboca, Município de Urucânia - MG, com altitude média de $422 \mathrm{~m}$, definido pelas coordenadas geográficas de $20^{\circ} 40^{\prime}$ de latitude sul e $42^{\circ} 90^{\prime}$ de longitude Oeste. A média anual de temperatura do ar é de $23,8^{\circ} \mathrm{C}$, variando entre a média das máximas de $29,5^{\circ} \mathrm{C}$ e a média das mínimas de $15^{\circ} \mathrm{C}$. O clima, segundo a classificação de Köppen, é do tipo Cwa. A umidade relativa média do ar é de $64,7 \%$ e a precipitação pluviométrica média anual é de 1.369,6 mm, que se caracteriza por duas estações bem definidas, sendo $80 \%$ das chuvas entre outubro e março, correspondendo ao período chuvoso, e os $20 \%$ restantes entre os meses de abril e setembro,

R. Bras. Zootec., v.32, n.4, p.977-985, 2003 
correspondendo ao período seco (Coelho \& Ribeiro, 1988).

Quanto ao ciclo de produção, são classificadas em precoces, ou seja, atingem um percentual do valor de brix (sólidos solúveis) desejável mais cedo, comparativamente às seguintes variedades: RB765418, RB 855453, RB 855336, SP 80-1842 e SP 81-1763., e em intermediárias as demais: RB 855113, RB 739359, RB 867515, SP 79-2233 e SP 79-1011.

Os cortes foram realizados em 17 de maio, 16 de julho e 15 de setembro de 1998, cujo plantio foi realizado em março 1997. Foram colhidas dez amostras da planta inteira (colmo mais folhas) por variedade, sendo realizada uma desfolha em cada corte, para a retirada das folhas secas, como é normalmente feito quando se fornece esta forrageira aos animais. Estas amostras foram picadas em ensiladora estacionária para a obtenção de uma amostra composta, contendo aproximadamente três quilos, que foram devidamente empacotadas em sacos plásticos e armazenadas em freezer para posteriores análises.

As análises químico-bromatológicas e o ensaio de degradabilidade in situ foram realizados nas dependências do Laboratório de Nutrição Animal do Departamento de Zootecnia da Universidade Federal de Viçosa - MG.

Inicialmente as amostras foram pré-secadas em estufa de ventilação forçada à $60^{\circ} \mathrm{C}$, por 96 horas, para posterior moagem em peneira de $2 \mathrm{~mm}$, dando prosseguimento às análises.

As análises laboratoriais consistiram na determinação da matéria seca (MS), matéria orgânica (MO), matéria mineral $(\mathrm{MM})$, proteína bruta $(\mathrm{PB})$, extrato etéreo (EE), lignina (LIG), fibra em detergente neutro (FDN), fibra em detergente neutro corrigida para cinzas e proteína (FDNcp), fibra em detergente ácido (FDA), fracionamento dos carboidratos totais, proteína insolúvel em detergente neutro (PIDN), proteína insolúvel em detergente ácido (PIDA) e proteína solúvel em detergente neutro (PSDN) (Sniffen et al., 1992).

As análises de PB, EE, MO e MM foram realizadas seguindo os procedimentos padrões da Association of Official Analytical Chemists (AOAC, 1990), e as análises de FDN, FDA e LIG, conforme Van Soest et al. (1991).

As análises de brix da cana foram conduzidas no Laboratório de Análises da Usina de Jatiboca empregando o protocolo de Pagamento da Cana pelo teor de sacarose conforme descrito por Fernandes (2000). Para determinação dos valores de nutrientes digestíveis totais (NDT), procedeu-se aos cálculos de acordo com a seguinte fórmula (Weiss, 1993):

$\mathrm{NDT}=(\mathrm{PBDcp} \times \mathrm{PB})+($ EE $\times 2,25)+[0,98 \times$

$(100-$ FDNN - PB - Cinzas -EE -1)] + 0,75 x

$\{($ FDNN - Lig) x [1 - (Lig / FDNN $) 0,667]\}-7$

em que: PBDcp representa a proteína bruta digestível verdadeira, sendo para forragem expressa como PBDcp-f $=\mathrm{e}-0,012 \times$ PIDA e para concentrado igual a PBDcp-c $=1-0,004 \times$ PIDA; FDNN corresponde a FDN ajustado para nitrogênio, sendo determinado a partir da PIDN $=-8,77+(0,33 \times \mathrm{PB})$ $+(0,143 \times$ FDN $)$; PB, EE, PIDN e Lig como definidos anteriormente.

As incubações in situ para a estimação dos parâmetros cinéticos de degradação da FDN foram feitas utilizando a técnica do saco de náilon, proposta por Mehrez \& Orskov (1977). As amostras, moídas em peneira de $6 \mathrm{~mm}$, foram incubadas em sacos de náilon com $50 \mathrm{~mm}$ de abertura entre malhas, medindo $6 \times 14 \mathrm{~cm}$. Antes de receberem as amostras, os sacos foram lavados, e, em seguida, secados em estufa com ventilação forçada, durante $24 \mathrm{~h}$, a $55^{\circ} \mathrm{C}$. A seguir, foram pesados a quente e identificados. Nessa ocasião, colocaram-se 3,0 g de MS (15 mg de MS/cm2 do saco), em cada saco, em três repetições, para os seguintes tempos de incubação: 0, 6, 48 e 96 horas. A incubação foi realizada em três animais mestiços Holandês x Zebu, fistulados no rúmen, com idade média de 18 meses e peso médio de $300 \mathrm{~kg}$ com distribuição dos sacos em relação a animal, variedade e tempo de incubação, seguindo as recomendações de Sampaio (1994). Estes animais foram mantidos em regime de confinamento, alojados em baias individuais cobertas de $3 \times 3 \mathrm{~m}$ de área, providas de bebedouro, cochos de alvenaria e piso de concreto. Foi fornecida uma dieta à base de capim-elefante e cana-de-açúcar picados, à vontade, e um quilo de concentrado à base de farelo de soja, fubá de milho, farelo de trigo e mistura mineral, uma vez ao dia, mantendo uma relação volumoso:concentrado de 70:30.

Ao final de cada tempo de incubação, os sacos foram retirados do rúmen, armazenados sob refrigeração, sendo então lavados ao mesmo tempo, à mão em água corrente até que o líquido de lavagem fluísse incolor, e submetidos à fervura em detergente neutro por uma hora. Posteriormente, foram lavados com água quente e acetona para a retirada do excesso de detergente e, então, secados em estufa com ventilação forçada, a $60^{\circ} \mathrm{C}$, por 48 horas, sendo, em seguida, pesados para obtenção das curvas de desaparecimento da FDN. 
O desaparecimento da fibra em detergente neutro foi analisado de acordo com o seguinte modelo estatístico (Sampaio, 1994):

$\mathrm{Y}_{\mathrm{ijkl}}=\mu+\mathrm{T}_{\mathrm{i}}+\mathrm{P}_{\mathrm{j}}+\mathrm{A}_{\mathrm{k}}+\left(\mathrm{E}_{\mathrm{i}}\right)_{\mathrm{jk}}+\mathrm{V}_{\mathrm{l}}+\mathrm{TV}_{\mathrm{il}}+\left(\mathrm{E}_{\mathrm{i}}\right)_{\mathrm{jkl}}$ em que: $Y_{i j k l}$ corresponde ao valor da degradabilidade potencial da FDN da l-ésima variedade, incubada no i-ésimo tempo, no k-ésimo animal, durante o j-ésimo período experimental. Ti representa o efeito o i-ésimo tempo de incubação; $\mathrm{P}_{\mathrm{j}}$ corresponde ao j-ésimo período $(j=1,2$ e 3$) ; A_{k}$ equivale ao efeito do K-ésimo animal $(\mathrm{k}=1,2$ e 3$) ;\left(E_{\mathrm{i}}\right)_{\mathrm{jk}}$ corresponde ao erro (a); $\mathrm{V}$ l equivale ao efeito da variedade $(1=1,2, \ldots, 10)$; TVil corresponde ao efeito da interação tempo de incubação x variedade; e $\left(\mathrm{E}_{\mathrm{i}}\right)_{\mathrm{jkl}}$ representa o erro (b).

Para a interpretação dos perfis de degradação utilizou-se o modelo assintótico exponencial decrescente de primeira ordem, conforme Mertens (1993):

$$
\mathrm{Y}=\mathrm{B} \exp ^{-\mathrm{ct}}+\mathrm{I}
$$

em que: $\mathrm{Y}$ é o resíduo no tempo t; $\mathrm{B}$ corresponde à fração potencialmente degradável; c é a taxa de degradação, t equivale aos tempos de incubação e I representa a fração não-degradável.

No ajustamento do modelo ao perfil de cada unidade experimental, visando à garantia de graus de liberdade suficiente para o procedimento iterativo empregado, adotou-se a pressuposição de nãosolubilização ou não-degradação da fração fibrosa do alimento instantaneamente, fazendo-se, portanto, o resíduo no tempo zero idêntico à massa incubada. Empregou-se o algoritmo iterativo de Gauss-Newton modificado (Souza, 1998).

O efeito de repleção ruminal das frações potencialmente degradável (RR1) e não-degradável da FDN (RR2) foi estimado adaptando-se os procedimentos descritos por Waldo et al. (1972), segundo as equações:

$$
\begin{gathered}
\mathrm{RR}_{1}(\mathrm{~h})=\lim _{\mathrm{t}} \rightarrow 8 \int_{0}^{t} \mathrm{~B}_{\mathrm{p}} \exp ^{-(\mathrm{c}+\mathrm{k})} \mathrm{t} \mathrm{d}_{\mathrm{t}} \\
\mathrm{RR}_{2}(\mathrm{~h})=\lim _{\mathrm{t}} \rightarrow 8 \int_{0}^{t} \operatorname{Ip} \exp ^{-\mathrm{kt}} \mathrm{d}_{\mathrm{t}} ; \mathrm{e} \\
\mathrm{RR}_{\mathrm{t}}(\mathrm{h})=\mathrm{RR}_{1}+\mathrm{RR}_{2}
\end{gathered}
$$

em que: $R R t=$ efeito de enchimento total; $\mathrm{Bp}=$ fração decimal padronizada potencialmente degradável $[\mathrm{Bp}=\mathrm{B} /(\mathrm{B}+\mathrm{I})]$; Ip = fração decimal padronizada indegradável $[\mathrm{Ip}=\mathrm{I} /(\mathrm{B}+\mathrm{I})] ; \mathrm{c}=$ taxa de degradação de $\mathrm{Bp}\left(\mathrm{h}^{-1}\right) ; \mathrm{t}=$ tempos de incubação (horas); $\mathrm{k}=$ taxa de passagem das partículas do alimento no rúmen $\left(\mathrm{h}^{-1}\right)$.

R. Bras. Zootec., v.32, n.4, p.977-985, 2003
Para a taxa de passagem da cana-de-açúcar no rúmen $(\mathrm{k})$ adotou-se o valor de 0,0202 (h-1), determinado por Pereira et al. (2001).

As análises estatísticas foram realizadas segundo o modelo:

$\mathrm{Y}_{\mathrm{ijk} k}=\mu+\mathrm{M}_{\mathrm{i}}+\mathrm{C}_{\mathrm{j}}+\mathrm{MC}_{\mathrm{ij}}+\mathrm{V}(\mathrm{i}) \mathrm{k}+\mathrm{e}_{(\mathrm{ijk}) 1}$ em que, $Y_{\mathrm{ijkl}}$ é o valor observado para o i-ésimo ciclo de produção da cana-de-açúcar, na j-ésima idade de corte da k-ésima variedade; $\mathrm{m}$ é a constante geral; $\mathrm{M}_{\mathrm{i}}$ é o efeito do ciclo de produção; $\mathrm{C}_{\mathrm{j}}$ é o efeito da idade de corte; $\mathrm{MC}_{\mathrm{ij}}$ é a interação do ciclo de produção i com a idade de corte $\mathrm{j}$; V(i)k é o efeito da variedade $\mathrm{k}$ dentro do ciclo de produção i e $e_{(i j k) 1}$ é o erro aleatório, pressuposto normal e independentemente distribuído, com média 0 e variância $\sigma^{2}$ (Searle, 1971).

As comparações entre médias de tratamentos de níveis qualitativos (ciclos de produção) foram feitas por intermédio do testes $\mathrm{F}$ e de Student-NewmanKeulls (SNK). De outra forma, os efeitos de natureza quantitativa (idade de corte) foram avaliados por análise de regressão linear, adotando-se, para tal, a conversão das datas de corte ao calendário juliano. $\mathrm{O}$ coeficiente de determinação das equações ajustadas foi calculado de forma parcial, segundo descrito por Carter e Grovum (1990):

$$
\mathrm{r}^{2} / \mathrm{R}^{2}=\frac{S Q E R}{S Q E R+S Q R}
$$

em que: SQER corresponde a somas de quadrados para os efeitos de regressão e SQR é igual à soma de quadrado residual.

Para análise dos dados, foi utilizado o Sistema de Análises Estatísticas e Genéticas - SAEG (Universidade Federal de Viçosa, 2000), adotando-se a até 0,05.

\section{Resultados e Discussão}

A produção e a composição químicobromatológica da cana-de-açúcar está representada na Tabela 1, bem como suas respectivas equações de regressão das variáveis que não apresentaram significância para a interação entre idade de corte e ciclo de produção.

Observa-se que as variedades de cana-de-açúcar com ciclo de produção intermediário tiveram uma produção 8, $66 \%$ maior $(\mathrm{P}<0,0001)$ que as precoces, sendo o efeito da idade de corte positivamente correlacionado com a produção.

Para os teores de MS, não houve diferença quanto aos ciclos de produção (precoces e interme- 
Tabela 1 - Produção, composição químico-bromatológica e equações de regressão ( $\hat{y}$ ) para cana-de-açúcar, considerando os efeitos do ciclo de produção e idade de corte

Table 1 - Production and chemical composition and regression equation $(\hat{y})$ for sugar cane, in function of the cycle of production and cut time effects

\begin{tabular}{|c|c|c|c|c|c|c|c|}
\hline \multirow[t]{2}{*}{$\overline{\text { Itens }}$} & \multicolumn{2}{|c|}{$\begin{array}{l}\text { Ciclo de produção } \\
\text { Cycle of production }\end{array}$} & \multicolumn{3}{|c|}{$\begin{array}{c}\text { Idade de corte (dias) } \\
\text { Cut time (days) }\end{array}$} & \multirow[t]{2}{*}{$\begin{array}{c}\text { Equações ajustadas } \\
\text { Adjusted equations }^{7}\end{array}$} & \multirow[t]{2}{*}{$\mathrm{r}^{2} / \mathrm{R}^{2}$} \\
\hline & $\begin{array}{l}\text { Precoce } \\
\text { Early }\end{array}$ & $\begin{array}{l}\text { Intermediária } \\
\text { Intermediate }\end{array}$ & 426 & 487 & 549 & & \\
\hline $\begin{array}{l}\mathrm{MS}(\%)^{1} \\
D M(\%)\end{array}$ & 28,72 & 28,69 & 27,02 & 29,73 & 29,38 & - & - \\
\hline $\begin{array}{l}\mathrm{NDT}^{2} \\
T D N\end{array}$ & $62,47^{b}$ & $63,51^{\mathrm{a}}$ & 62,45 & 63,02 & 63,50 & $\hat{y}=61,36+0,0087^{* *} \mathrm{X}$ & 0,1081 \\
\hline $\begin{array}{l}\mathrm{MM}^{3} \\
M M\end{array}$ & $16,12^{\mathrm{a}}$ & $15,64^{\mathrm{a}}$ & 17,96 & 16,43 & 13,26 & $\hat{y}=2,32064-0,039165^{* *} \mathrm{X}$ & 0,3413 \\
\hline $\begin{array}{l}\mathrm{FDN}^{3} \\
N D F\end{array}$ & $487,56^{a}$ & $471,03^{b}$ & 476,56 & 485,33 & 476,00 & $\hat{y}=39,83+0,0935 \mathrm{~ns} \mathrm{X}-0,00025^{*} \mathrm{X}^{2}$ & 0,0576 \\
\hline $\begin{array}{l}\mathrm{LG} 4 \\
L I G\end{array}$ & $13,46^{\mathrm{a}}$ & $13,36^{\mathrm{a}}$ & 14,25 & 12,85 & 13,13 & $\hat{y}=22,70-0,0960 * * \mathrm{X}+0,00023 * * \mathrm{X}^{2}$ & 0,1758 \\
\hline $\begin{array}{l}\mathrm{FDA}^{3} \\
A D F\end{array}$ & $287,87^{\mathrm{a}}$ & $274,54^{b}$ & 267,19 & 293,11 & 283,31 & $\hat{y}=9,45+0,1990 * * X-0,000496^{* *} \mathrm{X}^{2}$ & 0,3451 \\
\hline $\begin{array}{l}\mathrm{PIDN}^{5} \\
P I D N\end{array}$ & $13,55^{\mathrm{a}}$ & $14,06^{\mathrm{a}}$ & 14,77 & 12,96 & 13,69 & $\hat{y}=26,94-0,1405 \mathrm{~ns} \mathrm{X}+0,00031 * \mathrm{X}^{2}$ & 0,1002 \\
\hline $\begin{array}{l}\text { PIDA }^{5} \\
\text { PIDA }\end{array}$ & $2,91^{\mathrm{a}}$ & $2,94^{\mathrm{a}}$ & 3,05 & 2,81 & 2,90 & $\hat{y}=2,922808$ & - \\
\hline $\begin{array}{l}\operatorname{PSDN}^{5} \\
P S D N\end{array}$ & $86,45^{\mathrm{a}}$ & $85,94^{\mathrm{a}}$ & 85,23 & 87,04 & 86,31 & $\hat{y}=73,06+0,1405 n s X-0,00035^{*} X^{2}$ & 0,0991 \\
\hline $\begin{array}{l}\text { Prod }^{8} \\
\text { Prod }\end{array}$ & $126,30^{\mathrm{b}}$ & $137,24^{\mathrm{a}}$ & 121,16 & 136,15 & 138,00 & $\hat{y}=105,533+0,1403^{* *} X$ & 0,5431 \\
\hline
\end{tabular}

1 Média e erro-padrão da média.

$2 \%$ da MS.

$3 \mathrm{~g} / \mathrm{kg}$ MS.

$4 \%$ FDN.

$5 \%$ PB.

6 Médias na linha, relativas ao ciclo de produção, seguidas por letras diferentes, são diferentes $(P<0,05)$ pelo teste $F$.

$7 \mathrm{~ns},{ }^{*},{ }^{* *}$ : não-significativo e significativo a 5 e $1 \%$ de probabilidade pelo teste $\mathrm{t}$, respectivamente.

8 Produção (toneladas por hectare).

1 Mean and standard error of the mean.

$2 \%$ of DM.

$3 \mathrm{~g} / \mathrm{kg}$ of $D M$.

$4 \%$ of NDF.

$5 \%$ of $C P$.

6 Means, within a row, according to cycle of production, followed by different letters, are different $(P<.05)$ by $F$ test.

7 ns, *, **: not significant and significant at 5 and $1 \%$ of probability by $t$ test, respectively.

8 Production (t/hectare).

diárias) e para idade de corte. Entretanto, ao primeiro corte (426 dias) o teor foi, em média, 9,5\% menor que ao segundo e terceiro cortes (487 e 549 dias, respectivamente). Esta diferença pode ser explicada pelo aumento da capacidade fotossintética das plantas e pela perda de umidade, principalmente nas folhas, que normalmente ocorre na época seca. Estes valores de MS estão em concordância com maioria dos trabalhos apresentados na literatura (Aroeira, et al. 1992; Carvalho 1992; Pereira et al., 1996; Miranda et al. 1999; Rodrigues \& Barbosa, 1999; Pereira et al., 2001).

As variedades de cana-de-açúcar com ciclo de produção intermediário apresentaram valores de NDT maiores do que os das variedades precoces, o que pode ser atribuído à sua menor concentração em FDA, uma vez que a lignina se concentra na fração de FDA e, conseqüentemente, esta variável tem sido altamente correlacionada com a digestibilidade (Mertens, 1987). Adicionalmente, os menores teores

R. Bras. Zootec., v.32, n.4, p.977-985, 2003 
em FDN das espécies intermediárias, provavelmente, apresentariam menor efeito negativo sobre o consumo (Mertens, 1987 \& Van Soest, 1994), em relação às espécies precoces, quando colhidas na mesma idade. Observou-se também aumento linear $(\mathrm{P}<0,003)$ do percentual do NDT com o avanço na idade de corte, justificado pela redução linear do teor de matéria mineral $(\mathrm{P}<0,0001)$ e o aumento do brix (Tabela 2) com a idade, pois o NDT é estimado com base nos nutrientes orgânicos; embora não se tenha notado redução nos teores de FDN, o que era esperado, como conseqüência do aumento do teor de NDT.

Como esperado, as variedades de cana-de-açúcar precoces apresentaram maiores teores de FDN e FDA do que as intermediárias, uma vez que as primeiras atingem a maturidade mais cedo, culminando com o mais rápido desenvolvimento de estruturas de sustentação, que são representadas pelos polissacarídeos da parede celular vegetal (Wilson, 1997). Este fato torna as variedades de maturação intermediária mais apropriadas ao consumo pelos animais, devido à negativa relação entre os teores de FDN e FDA dos alimentos e seu valor nutricional. Como citado anteriormente, embora a FDA seja mais comumente relacionada com a digestibilidade que a FDN, normalmente o aumento do teor de FDN na planta está associado ao espessamento da parede celular vegetal, o que tem sido sugerido por reduzir a área superficial disponível para ataque microbiano no rúmen (Jung \& Deetz, 1993; Mertens, 1993).

Embora o aumento da idade de corte tenha apresentado efeito quadrático sobre os teores de FDN e
FDA, normalmente, para a cana, o oposto é verificado, contrariamente às demais espécies forrageiras. Possivelmente, o aumento registrado entre o corte realizado aos 426 dias e o realizado aos 487 dias seja em razão de as plantas ainda estarem em crescimento vegetativo. Já a queda a partir do segundo corte talvez seja explicada pela "diluição" dos constituintes da parece celular vegetal com o expressivo aumento do teor de açúcares solúveis (brix), sendo o mesmo comportamento observado por Carvalho (1992). Entretanto, verifica-se que as diferenças nos teores de FDN e FDA são relativamente pequenas, considerando os intervalos de quatro meses entre os cortes, o que evidencia a capacidade de manter constante o seu valor nutritivo ao longo do tempo, contrariamente ao que ocorre com a maioria das espécies forrageiras tropicais (Lima \& Mattos, 1993).

Embora os teores de FDN e FDA tenham apresentado diferenças quanto aos ciclos de produção, a lignina não foi influenciada por este fator. Já para a idade de corte, a concentração de lignina foi influenciada quadraticamente, assim como o PIDN. Embora apresente baixo teor de PB, a cana-de-açúcar destaca-se pela elevada proporção da PSDN e pela baixa proporção da fração C, ou seja, apresenta elevada disponibilidade para o animal. Os valores encontrados para o PIDA, PIDN e PSDN estão próximos aos de 3,5, 18,6 e 81,4\%, respectivamente, observados por Pereira et al. (2001) em uma amostra de cana não especificada quanto ao ciclo de produção e idade de corte.

Para o teor de PB, somente para o corte realizado aos 549 dias, foi detectada diferença entre as varie-

Tabela 2 - Desdobramento da interação para os teores de PB, EE e Brix; equações de regressão $(\hat{y})$ para cana-deaçúcar, considerando os efeitos do ciclo de produção e idade de corte

Table 2 - Unfolding of the interaction for CP, ether extract and brix, regression equation $(\hat{y})$ for sugar cane, in function of the cycle of production and cut time effects

\begin{tabular}{|c|c|c|c|c|c|c|}
\hline \multirow[t]{2}{*}{ Item } & \multicolumn{2}{|c|}{$\begin{array}{r}\mathrm{PB}^{1} \\
C P\end{array}$} & \multicolumn{2}{|c|}{$\begin{array}{c}\mathrm{EE}^{1} \\
\text { Ether extract }\end{array}$} & \multicolumn{2}{|c|}{$\begin{array}{l}\text { Brix }^{2} \\
\text { Brix }\end{array}$} \\
\hline & $\begin{array}{l}\text { Precoce } \\
\text { Early }\end{array}$ & $\begin{array}{l}\text { Intermediário } \\
\text { Intermediate }\end{array}$ & $\begin{array}{c}\text { Precoce } \\
\text { Early }\end{array}$ & $\begin{array}{l}\text { Intermediário } \\
\text { Intermediate }\end{array}$ & $\begin{array}{l}\text { Precoce } \\
\text { Early }\end{array}$ & $\begin{array}{l}\text { Intermediário } \\
\text { Intermediate }\end{array}$ \\
\hline \multicolumn{7}{|c|}{ Idade de corte (dias) } \\
\hline $\begin{array}{l}\text { Cut time (days) } \\
426 \\
487 \\
549\end{array}$ & $\begin{array}{c}26,12^{\mathrm{a}} \\
26,94^{\mathrm{a}} \\
28,8^{\mathrm{a}}\end{array}$ & $\begin{array}{l}25,76^{\mathrm{a}} \\
27,34^{\mathrm{a}} \\
26,22^{\mathrm{b}}\end{array}$ & $\begin{array}{l}7,34^{\mathrm{a}} \\
6,76^{\mathrm{a}} \\
6,65^{\mathrm{a}}\end{array}$ & $\begin{array}{l}6,08^{\mathrm{b}} \\
6,98^{\mathrm{a}} \\
6,68^{\mathrm{a}}\end{array}$ & $\begin{array}{l}18,63^{\mathrm{a}} \\
19,85^{\mathrm{a}} \\
19,70^{\mathrm{b}}\end{array}$ & $\begin{array}{l}17,97^{\mathrm{a}} \\
20,35^{\mathrm{a}} \\
22,10^{\mathrm{a}}\end{array}$ \\
\hline $\begin{array}{l}\text { Equação }(\hat{y}) \\
\text { Equation }\end{array}$ & $\bar{y}=27,31$ & $\bar{y}=26,54$ & $\bar{y}=6,91$ & $\bar{y}=6,87$ & $\bar{y}=19,39$ & $\bar{y}=20,14$ \\
\hline
\end{tabular}

Médias na mesma linha, seguidas por letras iguais, não diferem $(P>0,05)$ pelo teste SNK.

Means within a row, followed by different letters are different $(P<.05)$ by Tukey test.

${ }^{1} \mathrm{~g} / \mathrm{kg}$ de $\mathrm{MS}$ (g/kg DM).

$2 \%$ da cana (\% cane).

\section{R. Bras. Zootec., v.32, n.4, p.977-985, 2003}


dades precoces e intermediárias. Entretanto, pelo fato de as variedades precoces atingirem a maturidade mais cedo do que as intermediárias, o que é confirmado pelo maior teor de FDN e FDA nestas, esperar-se-ia redução do teor de PB. Adicionalmente, com a maturação, ocorre maior desenvolvimento do colmo em relação ao número de folhas, as quais apresentam maior concentração de PB que o colmo. Sendo assim, com o avanço da maturação, aumentase a proporção de colmo:folha, reduzindo-se, dessa forma, o percentual de PB (Lovadini, 1971). Entretanto, durante a fase de crescimento vegetativo, devido à maior taxa de crescimento das variedades precoces em relação às intermediárias estas provavelmente, apresentem maior proporção de folhas numa mesma idade de corte, o que explicaria o maior teor de PB. Porém, apesar das variações apresentadas, o teor de $\mathrm{PB}$ não auxilia na escolha de variedades de cana-de-açúcar, considerando-se que é característica dessa forrageira, o baixo conteúdo em compostos nitrogenados.

Embora tenha ocorrido interação entre o ciclo de produção e a idade de corte quanto ao teor de EE, onde no primeiro corte as variedades precoces apresentaram maior teor que as intermediárias, devido ao baixo teor deste na cana-de-açúcar, pode-se inferir que esta variação não afetaria o processo de seleção de variedades de cana-de-açúcar.

Para o brix foram verificadas interações entre os ciclos de produção e a idade ao corte correspondente a 549 dias, em que as variedades intermediárias apresentaram maior porcentagem em relação às precoces. Este comportamento era esperado, uma vez que as variedades precoces exibiram maior teor de FDN, haja vista a negativa relação entre brix e FDN. Embora o desdobramento da interação não tenha apontado variação significativa para o brix, dentro de cada nível do ciclo de produção, a avaliação conjunta de ambos os níveis do ciclo de produção indicou elevação linear $(\mathrm{P}<0,01)$ do teor de brix em razão da idade de corte, conforme exposto na Figura 2.

Este comportamento para o brix também foi observado por Carvalho (1992), que destaca a importante característica da cana-de-açúcar em aumentar sua concentração de sacarose na época seca do ano, justamente quando há escassez de forragens verdes, tornando-a uma forrageira com vantagens no que diz respeito ao fornecimento de energia. Além disso, o cálculo do teor de brix na cana é feito por meio de uma análise rápida, não onerosa e de fácil obtenção, que

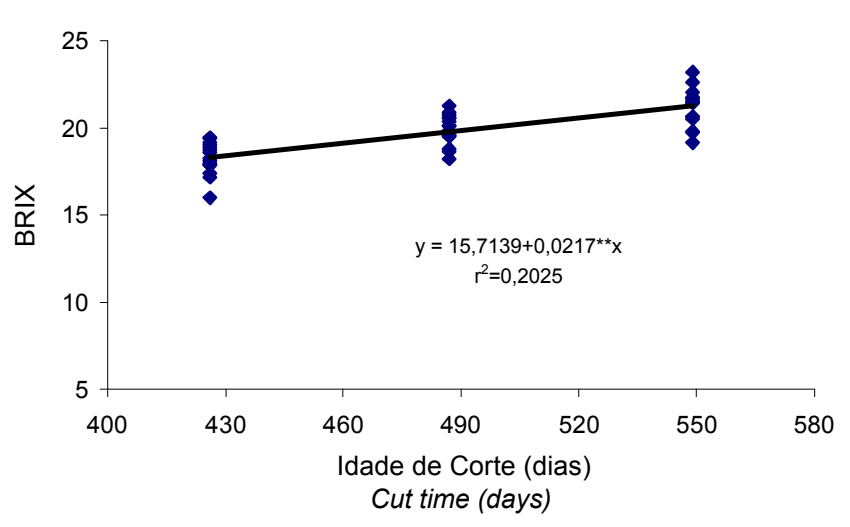

Figura 2 - Estimativas do teor de Brix em razão da idade ao corte ${ }^{* *}$ - significativo a $1 \%$ de probabilidade pelo teste $\mathrm{t}$ ).

Figure 2 - Estimates of brix contents according to cut time $\left({ }^{* *}\right.$ - significant at $1 \%$ of probability by $t$ test).

entretanto, não tem sido referenciada nos trabalhos de avaliação do valor nutricional da cana-de-açúcar.

$\mathrm{Na}$ Tabela 3, são apresentados os parâmetros cinéticos da degradação da FDN da cana-de-açúcar de acordo com o ciclo de produção e da idade de corte.

Quanto ao ciclo de produção, somente a repleção ruminal total (RRt) e a taxa de degradação $(\mathrm{Kd})$ foram diferentes. A maior RRt observada para as variedades precoces está de acordo com a maior concentração de FDN e FDA notadas para estas variedades (Tabela 1). A RRt é uma importante medida mecanicista que avalia a FDN quanto à sua disponibilidade e taxa de desaparecimento, que afeta a passagem das partículas no rúmen-retículo e, conseqüentemente, o consumo (Van Soest, 1994; Vieira et al., 1997). A menor taxa de degradação estimada para a FDN das variedades precoces pode ser atribuída ao mais rápido crescimento, que, embora não tenha refletido em maior concentração de lignina na FDN, deve ser lembrado que o espessamento da parede celular pode ser um fator crítico à degradação de gramíneas maduras (Jung \& Deetz, 1993; Mertens, 1993).

$\mathrm{O}$ avanço da idade de corte reduziu linearmente a fração potencialmente disponível da fibra (B0) e elevou a fração não-degradável (I0). O aumento do I0 acarretou maior efeito da repleção ruminal da fração indigerível (RRi), sendo estes resultados extremamente coerentes. Independentemente do ciclo de produção e da idade de corte, a cana-de-açúcar 
Tabela 3 - Parâmetros da cinética de degradação in situ da fibra em detergente neutro (FDN) e equações de regressão $(\hat{y})$ para cana-de-açúcar, considerando os efeitos do ciclo de produção e idade de corte

Table 3 - Parameters of the kinetics of in situ degradation of the fiber in neutral detergent (NDF) and regression equation ( $\hat{y}$ ) for sugar cane, considering the cycle of production and cut time effects

\begin{tabular}{|c|c|c|c|c|c|c|c|}
\hline \multirow[t]{2}{*}{ Itens } & \multicolumn{2}{|c|}{$\begin{array}{c}\text { Ciclo de produção } \\
\text { Cycle of production }\end{array}$} & \multicolumn{3}{|c|}{$\begin{array}{c}\text { Idade de corte (dias) } \\
\text { Cut time (days) }\end{array}$} & \multirow[t]{2}{*}{$\begin{array}{c}\text { Equações ajustadas } \\
{ }^{7} \\
\text { Adjusted equations }^{7}\end{array}$} & \multirow[t]{2}{*}{$2 / \mathrm{R}^{2}$} \\
\hline & $\begin{array}{c}\text { Precoce } \\
\text { Early }\end{array}$ & $\begin{array}{l}\text { Intermediária } \\
\text { Intermediate }\end{array}$ & 426 & 487 & 549 & & \\
\hline B0 & $41,11^{\mathrm{a}}$ & $41,29^{\mathrm{a}}$ & 42,66 & 42,54 & 39,80 & $\hat{y}=30,9497-0,1561 * X$ & 0,1863 \\
\hline I0 & $58,89^{\mathrm{a}}$ & $58,71^{\mathrm{a}}$ & 57,34 & 57,46 & 60,20 & $\hat{y}=54,4029+0,022956^{*} \mathrm{X}$ & 0,0551 \\
\hline $\mathrm{RRb}$ & $9,21^{\mathrm{a}}$ & $8,22^{\mathrm{a}}$ & 8,36 & 10,37 & 8,32 & $\hat{y}=-9,2540+0,2102 \mathrm{~ns} X-0,000563^{*} * \mathrm{X}^{2}$ & 0,2631 \\
\hline RRi & $29,13^{\mathrm{a}}$ & $28,92^{\mathrm{a}}$ & 28,41 & 28,65 & 30,02 & $\hat{y}=26,5268+0,01338 * * \mathrm{X}$ & 0,0999 \\
\hline RRt & $38,34^{\mathrm{a}}$ & $37,75^{\mathrm{b}}$ & 36,78 & 39,02 & 38,34 & $\hat{y}=22,3870+0,16487 * * \mathrm{X}-0,000406^{* *} \mathrm{X} 2$ & 0,3459 \\
\hline $\mathrm{Kd}$ & $0,0260^{b}$ & $0,0289^{\mathrm{a}}$ & 0,0032 & 0,0214 & 0,0286 & $\hat{y}=0,1142-0,00096^{*} \mathrm{X}+0,0000025^{* *} \mathrm{X}^{2}$ & 0,3401 \\
\hline
\end{tabular}

${ }^{1}$ B0 - Fração potencialmente degradável (\%) (Bo - potentially degradable fraction - \%); I0 - Fração não-degradável (\%) (I0 - Undegradable fraction - \%); RRb - efeito da repleção ruminal da fração potencialmente degradável (h) (RRt - effect of ruminal fill of potentialy degradable fraction - $h$ ); $\mathrm{RRi}$ - efeito da repleção ruminal da fração não-degradável (h) (RRi -effect of ruminal fill of undegradable fraction - $h$ ); RRt - efeito da repleção ruminal total $(\mathrm{h})$ (RRt - effect of total ruminal fill - $h)$; Kd - taxa de digestão $\left(\mathrm{h}^{-1}\right)\left(K d\right.$ - digestion rate- $\left.h^{-1}\right)$.

Média e erro-padrão da média (Mean and standard error of the mean).

2 Médias na linha, relativas ao ciclo de produção, seguidas por letras difererntes, são diferentes $(P<0,05)$ pelo teste $F$.

$3 \mathrm{~ns},{ }^{*},{ }^{* *}$ : não-significativo e significativo a de 5 e $1 \%$ de probabilidade pelo teste t, respectivamente.

${ }^{2}$ Means, with in a row, according to the cycle of production, followed by different letters, are different $(P<.05)$ by $F$ test.

${ }^{3} \mathrm{~ns},{ }^{*},{ }^{* *}$ : not significant and significant at 5 and $1 \%$ of probability by $t$ test, respectively.

destaca-se por apresentar elevada proporção nãodegradável da FDN (I0), característica esta que tem limitado a sua utilização para animais de elevado potencial de produção, devido aos efeitos negativos que esta fração exerce sobre a ingestão voluntária de alimentos (Mertens, 1987).

\section{Conclusões}

As variedades de cana-de-açúcar de ciclo de produção intermediário apresentaram melhor valor nutricional que as precoces, caracterizadas pelos menores teores de FDN e FDA, menor repleção ruminal total e maior porcentagem de NDT e brix.

$\mathrm{O}$ avanço da idade de corte acarretou redução da fibra potencialmente digestível, aumento da fração não-degradável e da repleção ruminal total.

\section{Literatura Citada}

AROEIRA, L.J.M., SILVEIRA, M.I., LIZIEIRE, R.S. et al. Degrababilidade no rúmen e taxa de passagem da cana-deaçúcar mais uréia, do farelo de algodão e do farelo de arroz em novilhos mestiços europeu x zebu. Revista Brasileira de Zootecnia, v.22, n.4, p.52-564, 1993.

ASSOCIATION OF OFFICIAL ANALYTICAL CHEMISTS AOAC. 1990. Official methods of analysis. v.1. 15.ed., Arlington, Virginia. $1117 \mathrm{p}$.

BOIN, C. Cana-de-açúcar na alimentação de ruminantes. In: SIMPÓSIO SOBRE NUTRIÇÃO DE BOVINOS, 5.,1995,
São Paulo. Anais...Piracicaba: Fundação de Estudos Agrários Luiz de Queiroz, 1995. p.177.

CARTER, R.R.; GROVUM, W.L. Factor affecting the voluntary intake of food by sheep. 5. The inhibitory effect of hipertononicity in the rúmen. British Journal of Nutrition, v.64, n.2, p.285-299, 1990.

CARVALHO, G.J. Avaliação do potencial forrageiro e industrial de variedades de cana-de-açúcar (ciclo de ano) em diferentes épocas de corte. Lavras: Universidade Federal de Lavras, 1992. 63p. Dissertação (Mestrado em Fitotecnia) Universidade Federal de Lavras, 1992.

COELHO, M.B.; RIBEIRO, S.N.N. Análise dos dados meteorológicos do Município de Ponte Nova - MG. Brasil Açucareiro, v.106, n.4, p.26-36, 1988.

FERNANDES, A.C. Cálculos na agroindústria da cana-deaçúcar, Piracicapa: STAB, 2000. p.193

JUNG, H.G.; DEETZ, D.A. Cell wall lignification and degradability. In: JUNG, H.G.; BUXTON, D.R.; HATIFIELD, R.D. et al. (Eds.) Forage cell wall structure and digestibility. Madison: America Society of Agronomy, Crop Society of America, Soil Society of America, 1993. p.315-46.

LENG, R.A. Limitaciones metabolicas en la utilización de la caña de azúcar y sus derivados para el crecimiento y producción de leche en ruminantes. In: PRESTON, T.R.: ROSALES, M. (Eds.) Siculmas intensivos para la producción animal y energia renovable con recursos tropicales. Cali: CIPAV, 1988. p.1-24.

LIMA, M.L.M.; MATTOS, W.R.S. Cana-de-açúcar na alimentação de bovinos leiteiros. In: SIMPÓSIO SOBRE NUTRIÇÃO DE BOVINOS, 5., 1995, São Paulo. Anais...Piracicaba: Fundação de Estudos Agrários Luiz de Queiroz, 1995. p.177.

LOVADINI, L.A.C. Efeito da maturidade da planta sobre a composição em fibra bruta, celulose, lignina e digestibilidade da celulose in vitro, em variedades de canade-açúcar. Piracicaba: Escola Superior de Agricultura Luiz de Queiroz, 1971. 76p. Dissertação (Mestrado em Zootecnia) -

R. Bras. Zootec., v.32, n.4, p.977-985, 2003 
Escola Superior de Agricultura Luiz de Queiroz, 1971.

LUDOVICO, A.; MATTOS, W.R.S. Avaliação de dietas à base de cana-de-açúcar (Saccharum officinarum L.) e diferentes níveis de semente de algodão (Gossypium hirsutum L.). Revista Brasileira de Zootecnia, v.26, n.2, p.403-410, 1997.

MEHREZ, A.Z.; ORSKOV, E.R. A study of the artificial fiber bag techinique for determining the digestibility of feed in rúmen. Journal of Agricultural Science, v.88, n.3, p.654-660, 1977.

MERTENS, D.R. Rate and extent of digestion. In: FORBES, J.M.; FRANCE, J. (Eds.) Quantitative aspects of ruminant digestion and metabolism. Cambridge: Cambridge University Press, 1993. p.13-51.

MERTENS, D.R. Predicting intake and digestibility using mathematical models of ruminal function. Journal of Animal Science, v.64, n.5, p.1548-1558, 1987.

MIRANDA, L.F.; QUEIROZ, A.C.; VALADARES FILHO, S.C. et al. Desempenho e desenvolvimento ponderal de novilhas leiteiras alimentadas com dietas à base de canade-açúcar. Revista Brasileira de Zootecnia, v.28, n.3, p.605-613, 1999.

PEIXOTO, A.M. A cana-de-açúcar como recurso forrageiro. In: CONGRESSO BRASILEIRO DE PASTAGENS, 1986, São Paulo. Anais... Piracicaba: Fundação de Estudos Agrários Luiz de Queiroz, 1986. p.86.

PEREIRA, O.G.; GARCIA, R., VALADARES FILHO, S.C. et al. Consumo e digestibilidade total e parcial dos nutrientes de dietas contendo cana-de-açúcar (Saccharum officinarum L.), sob diferentes formas, em bovinos. Revista Brassileira de Zootecnia, v.25, n.4, p.750-762, 1996.

PEREIRA, E.S.; QUEIROZ, A.C.; PAULINO, M.F. et al. Fontes nitrogenadas e uso de Sacharomyces cereviseae em dietas à base de cana-de-açúcar para novilhos: Consumo, digestibilidade, balanço nitrogenado e parâmetros ruminais. Revista Brasileira de Zootecnia., v.30, n.2, p.563-572, 2001.

PRESTON, T.R. Whole sugarcane as animal feed: An overview. In: SANSOUCY, R.; AARTS, G.; PRESTON, T.R. (Eds.)FAO consultation sugar cane as feed. Rome: FAO, 1986. p.61-71.

RODRIGUES, A.A.; BARBOSA, P.F. Efeito do teor protéico do concentrado no consumo da cana-de-açúcar com uréia e ganho de peso de novilhas em crescimento. Revista Brasileira de Zootecnia, v.28, n.2, p.421-424, 1999.
SAMPAIO, I.B.M. Contribuições estatísticas e de técnica experimental para ensaios de degradabilidade de forragens quando avaliada in situ. In: REUNIÃO ANUAL DA SOCIEDADE BRASILEIRA DE ZOOTECNIA, 31., 1994, Maringá. Anais... Maringá: Sociedade Brasileira de Zootecnia, 1994. p.81-82.

SEARLE, S.R. Linear models. New York: John Wiley \& Sons, 1971. 532p.

SNIFFEN, C.J.; O'CONNOR, J.D.; Van SOEST, P.J. et al. A net carbohydrate and protein system for evaluating cattle diets. II. Carbohydrate and protein availability. Journal of Animal Science, v.70, n.7, p.3562-3577, 1992.

SOUZA, G.S. Introdução ao modelo de regressão linear e não linear. Brasília: EMBRAPA - STI, 1998. 505p.

UNIVERSIDADE FEDERAL DE VIÇOSA - UFV. SAEG Sistema de análise estatística e genética. Versão 8.0. Viçosa, MG. 2000.

Van SOEST, P.J.; ROBERTSON, J.B.; LEWIS, B.A. Methods for dietary fiber, neutral detergent fiber, and non starch polyssacarides in relation to animal nutrition. Journal of Dairy Science, v.74, n.10, p.3583-3597, 1991.

Van SOEST, P.J. Nutritional ecology of the ruminant. 2.ed. New York: Cornell University Press. 1994. 476p.

VIEIRA, R.A.; PEREIRA, J.C.; MALAFAIA, P.A.M. et al. The influence of elephantgrass (Pennisetum purpureum Schum Mineiro variety) growth on the nutrient kinetics in the rumen. Animal Feed Science and Technology, v.67, p.151-161, 1997.

WALDO, D.R; SMITH, L.W.; COX, E.L. Model of cellulose disappearance from the rumen. Journal of Dairy Science, v.55, n.1, p. 125-129, 1972.

WEISS, W.P. Method estimates available energy value for ruminants. Feedstuffs, v.9, p.13-14, 1993.

WILSON, J.R. Structural and anatomical traits of forages influencing their nutritive value for ruminants. In: SIMPÓSIO INTERNACIONAL SOBRE PRODUÇÃO ANIMAL EM PASTEJO, 1997, Viçosa, MG. Anais... Viçosa: Universidade Federal de Viçosa, 1997. p.173-208.

Recebido em: 04/12/01

Aceito em: 16/01/03 